\title{
Uniform Requirements for Manuscripts Submitted to Biomedical Journals: Writing and Editing for Biomedical Publication
}

\section{Updated October 2004}

International Committee of Medical Journal Editors

I. Statement of Purpose

A. About the Uniform Requirements

B. Potential Users of the Uniform Requirements

C. How to Use the Uniform Requirements

II. Ethical Considerations in the Conduct and Reporting of Research

A. Authorship and Contributorship

1. Byline Authors

2. Contributors Listed in Acknowledgements

B. Editorship

1. The Role of the Editor

2. Editorial Freedom

C. Peer Review

D. Conflicts of Interest

1. Potential Conflicts of Interest Related to Individual Authors' Commitments

2. Potential Conflicts of Interest Related to Project Support

3. Potential Conflicts of Interest Related to Commitments of Editors, Journal Staff, or Reviewers

E. Privacy and Confidentiality

1. Patients and Study Participants

2. Authors and Reviewers

F. Protection of Human Subjects and Animals in Research

III. Publishing and Editorial Issues Related to Publication In Biomedical Journals

A. Obligation to Publish Negative Studies

B. Corrections, Retractions, and "Expressions of Concern"

C. Copyright

D. Overlapping Publications

1. Duplicate Submission

2. Redundant Publication

3. Acceptable Secondary Publication

4. Competing Manuscripts based on the Same Study

a. Differences in Analysis or Interpretation

b. Differences in Reported Methods or Results

5. Competing Manuscripts Based on the Same Database

E. Correspondence

F. Supplements, Theme Issues, and Special Series

G. Electronic Publishing

H. Advertising

I. Medical Journals and the General Media

J. Obligation to Register Clinical Trials
IV. Manuscript Preparation and Submission

A. Preparing a Manuscript for Submission to Biomedical Journals

1. General Principles and Reporting Guidelines

a. General Principles

b. Reporting Guidelines for Specific Study Designs

2. Title page

3. Conflict of Interest Notification Page

4. Abstract and Key Words

5. Introduction

6. Methods

a. Selection and Description of Participants

b. Technical Information

c. Statistics

7. Results

8. Discussion

9. References

a. General Considerations Related to References

b. Reference Style and Format

10. Tables

11. Illustrations (Figures)

12. Legends for Illustrations (Figures)

13. Units of Measurement

14. Abbreviations and Symbols

B. Sending the Manuscript to the Journal

V. References

A. Print References Cited in this Document

B. Other Sources of Information Related to Biomedical Journals

VI. About the International Committee of Medical Journal Editors

VII. Authors of the Uniform Requirements

VIII. Use, Distribution, and Translation of the Uniform Requirements

IX. Inquiries

\section{Statement Of Purpose}

I.A. About the Uniform Requirements

A small group of editors of general medical journals met informally in Vancouver, British Columbia, in 1978 to establish guidelines for the format of manuscripts submitted to their journals. The group became known as the Vancouver Group. Its requirements for manuscripts, including formats for bibliographic references developed by the National Library of Medicine, were first published in 1979. The Vancouver Group expanded and evolved into the International Committee of Medical Journal Editors 
ICMJE Uniform Requirements for Manuscripts Submitted to Biomedical Journals: Writing and Editing for Biomedical Publication

(ICMJE), which meets annually. The ICMJE gradually has broadened its concerns to include ethical principles related to publication in biomedical journals.

The ICJME has produced multiple editions of the Uniform Requirements for Manuscripts Submitted to Biomedical Journals. Over the years, issues have arisen that go beyond manuscript preparation, resulting in the development of a number of Separate Statements on editorial policy. The entire Uniform Requirements document was revised in 1997; sections were updated in May 1999 and May 2000. In May 2001, the ICMJE revised the sections related to potential conflict of interest. In 2003, the committee revised and reorganized the entire document and incorporated the Separate Statements into the text. The committee prepared this revision in 2004.

The total content of the Uniform Requirements for Manuscripts Submitted to Biomedical Journals may be reproduced for educational, not-for-profit purposes without regard for copyright; the committee encourages distribution of the material.

Journals that agree to use the Uniform Requirements are encouraged to state in their instructions to authors that their requirements are in accordance with the Uniform Requirements and to cite this version.

\section{I.B. Potential Users of the Uniform Requirements}

The ICMJE created the Uniform Requirements primarily to help authors and editors in their mutual task of creating and distributing accurate, clear, easily accessible reports of biomedical studies. The initial sections address the ethical principles related to the process of evaluating, improving, and publishing manuscripts in biomedical journals and the relationships between editors and authors, peer reviewers, and the media. The latter sections address the more technical aspects of preparing and submitting manuscripts. The ICMJE believes the entire document is relevant to the concerns of both authors and editors.

The Uniform Requirements can provide many other stakeholders-peer reviewers, publishers, the media, patients and their families, and general readers - with useful insights into the biomedical authoring and editing process.

\section{I.C. How to Use the Uniform Requirements}

The Uniform Requirements state the ethical principles in the conduct and reporting of research and provide recommendations relating to specific elements of editing and writing. These recommendations are based largely on the shared experience of a moderate number of editors and authors, collected over many years, rather than on the results of methodical, planned investigation that aspires to be "evidence-based." Wherever possible, recommendations are accompanied by a rationale that justifies them; as such, the document serves an educational purpose.

Authors will find it helpful to follow the recommendations in this document whenever possible because, as described in the explanations, doing so improves the qual- ity and clarity of reporting in manuscripts submitted to any journal, as well as the ease of editing. At the same time, every journal has editorial requirements uniquely suited to its purposes. Authors therefore need to become familiar with the specific instructions to authors published by the journal they have chosen for their manuscript-for example, the topics suitable for that journal, and the types of papers that may be submitted (for example, original articles, reviews, or case reports) — and should follow those instructions. The Mulford Library at the Medical College of Ohio maintains a useful compendium of instructions to authors at www.mco.edu/lib/instr/libinsta.html.

\section{Ethical Considerations in the Conduct and REPORTING OF RESEARCH \\ II.A Authorship and Contributorship II.A.1. Byline Authors}

An "author" is generally considered to be someone who has made substantive intellectual contributions to a published study, and biomedical authorship continues to have important academic, social, and financial implications. (1) In the past, readers were rarely provided with information about contributions to studies from those listed as authors and in acknowledgments. (2) Some journals now request and publish information about the contributions of each person named as having participated in a submitted study, at least for original research. Editors are strongly encouraged to develop and implement a contributorship policy, as well as a policy on identifying who is responsible for the integrity of the work as a whole.

While contributorship and guarantorship policies obviously remove much of the ambiguity surrounding contributions, it leaves unresolved the question of the quantity and quality of contribution that qualify for authorship. The International Committee of Medical Journal Editors has recommended the following criteria for authorship; these criteria are still appropriate for those journals that distinguish authors from other contributors.

- Authorship credit should be based on 1) substantial contributions to conception and design, or acquisition of data, or analysis and interpretation of data; 2) drafting the article or revising it critically for important intellectual content; and 3) final approval of the version to be published. Authors should meet conditions 1, 2, and 3 .

- When a large, multi-center group has conducted the work, the group should identify the individuals who accept direct responsibility for the manuscript (3). These individuals should fully meet the criteria for authorship defined above and editors will ask these individuals to complete journal-specific author and conflict of interest disclosure forms. When submitting a group author manuscript, the corresponding author should clearly indicate the preferred citation and should clearly identify all individual authors as well as the group 
Uniform Requirements for Manuscripts Submitted to Biomedical Journals: Writing and Editing for Biomedical Publication $\mid$ ICMIE

name. Journals will generally list other members of the group in the acknowledgements. The National Library of Medicine indexes the group name and the names of individuals the group has identified as being directly responsible for the manuscript.

- Acquisition of funding, collection of data, or general supervision of the research group, alone, does not justify authorship.

- All persons designated as authors should qualify for authorship, and all those who qualify should be listed.

- Each author should have participated sufficiently in the work to take public responsibility for appropriate portions of the content.

Some journals now also request that one or more authors, referred to as "guarantors," be identified as the persons who take responsibility for the integrity of the work as a whole, from inception to published article, and publish that information.

Increasingly, authorship of multi-center trials is attributed to a group. All members of the group who are named as authors should fully meet the above criteria for authorship.

The order of authorship on the byline should be a joint decision of the co-authors. Authors should be prepared to explain the order in which authors are listed.

\section{II.A.2. Contributors Listed in Acknowledgments}

All contributors who do not meet the criteria for authorship should be listed in an acknowledgments section. Examples of those who might be acknowledged include a person who provided purely technical help, writing assistance, or a department chair who provided only general support. Financial and material support should also be acknowledged.

Groups of persons who have contributed materially to the paper but whose contributions do not justify authorship may be listed under a heading such as "clinical investigators" or "participating investigators," and their function or contribution should be described-for example, "served as scientific advisors," "critically reviewed the study proposal," "collected data," or "provided and cared for study patients."

Because readers may infer their endorsement of the data and conclusions, all persons must give written permission to be acknowledged.

\section{II.B Editorship}

\section{II.B.1. The Role of the Editor}

The editor of a journal is the person responsible for its entire content. Owners and editors of medical journals have a common endeavor-the publication of a reliable and readable journal, produced with due respect for the stated aims of the journal and for costs. The functions of owners and editors, however, are different. Owners have the right to appoint and dismiss editors and to make important business decisions in which editors should be in- volved to the fullest extent possible. Editors must have full authority for determining the editorial content of the journal. This concept of editorial freedom should be resolutely defended by editors even to the extent of their placing their positions at stake. To secure this freedom in practice, the editor should have direct access to the highest level of ownership, not only to a delegated manager.

Editors of medical journals should have a contract that clearly states the editor's rights and duties in addition to the general terms of the appointment and that defines mechanisms for resolving conflict.

An independent editorial advisory board may be useful in helping the editor establish and maintain editorial policy.

\section{II.B.2. Editorial Freedom}

The ICMJE adopts the World Association of Medical Editors' definition of editorial freedom (http://www.wame .org/wamestmt.htm). This definition states that editorial freedom or independence is the concept that editors-in chief should have full authority over the editorial content of their journal. Journal owners should not interfere in the evaluation; selection or editing of individual articles either directly or by creating an environment that strongly influences decisions. Editors should base decisions on the validity of the work and its importance to the journal's readers not on the commercial success of the journal. Editors should be free to express critical but responsible views about all aspects of medicine without fear of retribution, even if these views might conflict with the commercial goals of the publisher. Editors and editors' organizations have the obligation to support the concept of editorial freedom and to draw major transgressions of such freedom to the attention of the international medical, academic, and lay communities.

\section{II.C. Peer Review}

Unbiased, independent, critical assessment is an intrinsic part of all scholarly work, including the scientific process. Peer review is the critical assessment of manuscripts submitted to journals by experts who are not part of the editorial staff. Peer review can therefore be viewed as an important extension of the scientific process. Although its actual value has been little studied, and is widely debated (4), peer review helps editors decide which manuscripts are suitable for their journals, and helps authors and editors in their efforts to improve the quality of reporting. A peerreviewed journal is one that submits most of its published research articles for outside review. The number and kind of manuscripts sent for review, the number of reviewers, the reviewing procedures, and the use made of the reviewers' opinions may vary. In the interests of transparency, each journal should publicly disclose its policies in its instructions to authors.

\section{II.D. Conflicts of Interest}

Public trust in the peer review process and the credibility of published articles depend in part on how well conflict of interest is handled during writing, peer review, 
ICMJE Uniform Requirements for Manuscripts Submitted to Biomedical Journals: Writing and Editing for Biomedical Publication

and editorial decision making. Conflict of interest exists when an author (or the author's institution), reviewer, or editor has financial or personal relationships that inappropriately influence (bias) his or her actions (such relationships are also known as dual commitments, competing interests, or competing loyalties). These relationships vary from those with negligible potential to those with great potential to influence judgment, and not all relationships represent true conflict of interest. The potential for conflict of interest can exist whether or not an individual believes that the relationship affects his or her scientific judgment. Financial relationships (such as employment, consultancies, stock ownership, honoraria, paid expert testimony) are the most easily identifiable conflicts of interest and the most likely to undermine the credibility of the journal, the authors, and of science itself. However, conflicts can occur for other reasons, such as personal relationships, academic competition, and intellectual passion.

All participants in the peer review and publication process must disclose all relationships that could be viewed as presenting a potential conflict of interest. Disclosure of these relationships is also important in connection with editorials and review articles, because it is can be more difficult to detect bias in these types of publications than in reports of original research. Editors may use information disclosed in conflict of interest and financial interest statements as a basis for editorial decisions. Editors should publish this information if they believe it is important in judging the manuscript.

\section{II.D.1. Potential Conflicts of Interest Related to Individual Authors' Commitments}

When authors submit a manuscript, whether an article or a letter, they are responsible for disclosing all financial and personal relationships that might bias their work. To prevent ambiguity, authors must state explicitly whether potential conflicts do or do not exist. Authors should do so in the manuscript on a conflict of interest notification page that follows the title page, providing additional detail, if necessary, in a cover letter that accompanies the manuscript. (See Section IV.A.3. Conflict of Interest Notification Page)

Investigators must disclose potential conflicts to study participants and should state in the manuscript whether they have done so.

Editors also need to decide when to publish information disclosed by authors about potential conflicts. If doubt exists, it is best to err on the side of publication.

\section{II.D.2. Potential Conflicts of Interest Related to Project Support}

Increasingly, individual studies receive funding from commercial firms, private foundations, and government. The conditions of this funding have the potential to bias and otherwise discredit the research.

Scientists have an ethical obligation to submit creditable research results for publication. Moreover, as the persons directly responsible for their work, researchers should not enter into agreements that interfere with their access to the data and their ability to analyze it independently, to prepare manuscripts, and to publish them. Authors should describe the role of the study sponsor(s), if any, in study design; in the collection, analysis, and interpretation of data; in the writing of the report; and in the decision to submit the report for publication. If the supporting source had no such involvement, the authors should so state. Biases potentially introduced when sponsors are directly involved in research are analogous to methodological biases of other sorts. Some journals, therefore, choose to include information about the sponsor's involvement in the methods section.

Editors may request that authors of a study funded by an agency with a proprietary or financial interest in the outcome sign a statement such as, "I had full access to all of the data in this study and I take complete responsibility for the integrity of the data and the accuracy of the data analysis." Editors should be encouraged to review copies of the protocol and/or contracts associated with project-specific studies before accepting such studies for publication. Editors may choose not to consider an article if a sponsor has asserted control over the authors' right to publish.

\section{II.D.3. Potential Conflicts of Interest Related to Commitments of Editors, Journal Staff, or Reviewers}

Editors should avoid selecting external peer reviewers with obvious potential conflicts of interest, for example, those who work in the same department or institution as any of the authors. Authors often provide editors with the names of persons they feel should not be asked to review a manuscript because of potential conflicts of interest, usually professional. When possible, authors should be asked to explain or justify their concerns; that information is important to editors in deciding whether to honor such requests.

Reviewers must disclose to editors any conflicts of interest that could bias their opinions of the manuscript, and they should disqualify themselves from reviewing specific manuscripts if they believe it to be appropriate. As in the case of authors, silence on the part of reviewers concerning potential conflicts may mean either that such conflicts exist that they have failed to disclose, or that conflicts do not exist. Reviewers must therefore also be asked to state explicitly whether conflicts do or do not exist. Reviewers must not use knowledge of the work, before its publication, to further their own interests.

Editors who make final decisions about manuscripts must have no personal, professional, or financial involvement in any of the issues they might judge. Other members of the editorial staff, if they participate in editorial decisions, must provide editors with a current description of their financial interests (as they might relate to editorial judgments) and disqualify themselves from any decisions where they have a conflict of interest. Editorial staff must not use the information gained through working with manuscripts for private gain. Editors should publish regu- 
lar disclosure statements about potential conflicts of interests related to the commitments of journal staff.

\section{II.E. Privacy and Confidentiality \\ II.E.1. Patients and Study Participants}

Patients have a right to privacy that should not be infringed without informed consent. Identifying information, including patients' names, initials, or hospital numbers, should not be published in written descriptions, photographs, and pedigrees unless the information is essential for scientific purposes and the patient (or parent or guardian) gives written informed consent for publication. Informed consent for this purpose requires that a patient who is identifiable be shown the manuscript to be published.

Identifying details should be omitted if they are not essential. Complete anonymity is difficult to achieve, however, and informed consent should be obtained if there is any doubt. For example, masking the eye region in photographs of patients is inadequate protection of anonymity. If identifying characteristics are altered to protect anonymity, such as in genetic pedigrees, authors should provide assurance that alterations do not distort scientific meaning and editors should so note.

The requirement for informed consent should be included in the journal's instructions for authors. When informed consent has been obtained it should be indicated in the published article.

\section{II.E.2. Authors and Reviewers}

Manuscripts must be reviewed with due respect for authors' confidentiality. In submitting their manuscripts for review, authors entrust editors with the results of their scientific work and creative effort, on which their reputation and career may depend. Authors' rights may be violated by disclosure of the confidential details of the review of their manuscript. Reviewers also have rights to confidentiality, which must be respected by the editor. Confidentiality may have to be breached if dishonesty or fraud is alleged but otherwise must be honored.

Editors must not disclose information about manuscripts (including their receipt, content, status in the reviewing process, criticism by reviewers, or ultimate fate) to anyone other than the authors and reviewers. This includes requests to use the materials for legal proceedings.

Editors must make clear to their reviewers that manuscripts sent for review are privileged communications and are the private property of the authors. Therefore, reviewers and members of the editorial staff must respect the authors' rights by not publicly discussing the authors' work or appropriating their ideas before the manuscript is published. Reviewers must not be allowed to make copies of the manuscript for their files and must be prohibited from sharing it with others, except with the permission of the editor. Reviewers should return or destroy copies of manuscripts after submitting reviews. Editors should not keep copies of rejected manuscripts.
Reviewer comments should not be published or otherwise made public without permission of the reviewer, author, and editor.

Opinions differ on whether reviewers should remain anonymous. Authors should consult the information for authors of the journal they have chosen to learn whether the reviews are anonymous. When comments are not signed the reviewers' identity must not be revealed to the author or anyone else without the reviewer's permission.

Some journals publish reviewers' comments with the manuscript. No such procedure should be adopted without the consent of the authors and reviewers. However, reviewers' comments should be sent to other reviewers of the same manuscript, which helps reviewers learn from the review process, and reviewers may be notified of the editor's decision.

\section{II.F. Protection of Human Subjects and Animals in Research}

When reporting experiments on human subjects, authors should indicate whether the procedures followed were in accordance with the ethical standards of the responsible committee on human experimentation (institutional and national) and with the Helsinki Declaration of 1975, as revised in 2000 (5). If doubt exists whether the research was conducted in accordance with the Helsinki Declaration, the authors must explain the rationale for their approach, and demonstrate that the institutional review body explicitly approved the doubtful aspects of the study. When reporting experiments on animals, authors should be asked to indicate whether the institutional and national guide for the care and use of laboratory animals was followed.

\section{Publishing and Editorial Issues Related to Publication in Biomedical Journals III.A. Obligation to Publish Negative Studies}

Editors should consider seriously for publication any carefully done study of an important question, relevant to their readers, whether the results are negative (that is, convincingly allow the null hypothesis to be accepted) or positive (that is, allow the null hypothesis to be rejected). Failure to submit or publish negative studies, in particular, contributes to publication bias. Many studies that purport to be negative are, in fact, inconclusive; publication of inconclusive studies is problematic, since they add little to biomedical knowledge and consume journal resources. The Cochrane Library may be interested in publishing inconclusive trials (www.cochrane.org).

\section{III.B. Corrections, Retractions and "Expressions of Concern"}

Editors must assume initially that authors are reporting work based on honest observations. Nevertheless, two types of difficulty may arise.

First, errors may be noted in published articles that require the publication of a correction or erratum of part of the work. The corrections should appear on a numbered 
page, be listed in the contents page, include the complete original citation, and link to the original article and vice versa if online. It is conceivable that an error could be so serious as to vitiate the entire body of the work, but this is unlikely and should be handled by editors and authors on an individual basis. Such an error should not be confused with inadequacies exposed by the emergence of new scientific information in the normal course of research. The latter require no corrections or withdrawals.

The second type of difficulty is scientific fraud. If substantial doubts arise about the honesty or integrity of work, either submitted or published, it is the editor's responsibility to ensure that the question is appropriately pursued, usually by the authors' sponsoring institution. However, it is not ordinarily the task of editors to conduct a full investigation or to make a determination; that responsibility lies with the institution where the work was done or with the funding agency. The editor should be promptly informed of the final decision, and if a fraudulent paper has been published, the journal must print a retraction. If this method of investigation does not result in a satisfactory conclusion, the editor may choose to conduct his or her own investigation. As an alternative to retraction, the editor may choose to publish an expression of concern about aspects of the conduct or integrity of the work.

The retraction or expression of concern, so labeled, should appear on a numbered page in a prominent section of the print journal as well as in the online version, be listed in the contents page, and include in its heading the title of the original article. It should not simply be a letter to the editor. Ideally, the first author should be the same in the retraction as in the article, although under certain circumstances the editor may accept retractions by other responsible persons. The text of the retraction should explain why the article is being retracted and include a full original citation reference to it.

The validity of previous work by the author of a fraudulent paper cannot be assumed. Editors may ask the author's institution to assure them of the validity of earlier work published in their journals or to retract it. If this is not done editors may choose to publish an announcement expressing concern that the validity of previously published work is uncertain.

\section{III.C. Copyright}

Many biomedical journals ask authors to transfer copyright to the journal. However, an increasing number of "open access" journals do not require authors to transfer copyright to the journal. Editors should make their position on copyright transfer clear to authors and to others who might be interested in using editorial content from their journals. The copyright status of articles in a given journal can vary: some content cannot be copyrighted (articles written by employees of the U.S. and some other governments in the course of their work, for example); editors may agree to waive copyright on others; still others may be protected under serial rights (that is, use in publications other than journals, including electronic publications, is permitted).

\section{III.D. Overlapping Publications \\ III.D.1. Duplicate Submission}

Most biomedical journals will not consider manuscripts that are simultaneously being considered by other journals. Among the principal considerations that have led to this policy are: 1) the potential for disagreement when two (or more) journals claim the right to publish a manuscript that has been submitted simultaneously to more than one; and 2) the possibility that two or more journals will unknowingly and unnecessarily undertake the work of peer review and editing of the same manuscript, and publish same article.

However, editors of different journals may decide to simultaneously or jointly publish an article if they believe that doing so would be in the best interest of the public's health.

\section{III.D.2. Redundant Publication}

Redundant (or duplicate) publication is publication of a paper that overlaps substantially with one already published in print or electronic media.

Readers of primary source periodicals, whether print or electronic, deserve to be able to trust that what they are reading is original unless there is a clear statement that the article is being republished by the choice of the author and editor. The bases of this position are international copyright laws, ethical conduct, and cost-effective use of resources. Duplicate publication of original research is particularly problematic, since it can result in inadvertent double counting or inappropriate weighting of the results of a single study, which distorts the available evidence.

Most journals do not wish to receive papers on work that has already been reported in large part in a published article or is contained in another paper that has been submitted or accepted for publication elsewhere, in print or in electronic media. This policy does not preclude the journal considering a paper that has been rejected by another journal, or a complete report that follows publication of a preliminary report, such as an abstract or poster displayed at a professional meeting. Nor does it prevent journals considering a paper that has been presented at a scientific meeting but not published in full or that is being considered for publication in a proceedings or similar format. Press reports of scheduled meetings will not usually be regarded as breaches of this rule, but additional data or copies of tables and illustrations should not amplify such reports.

When submitting a paper, the author must always make a full statement to the editor about all submissions and previous reports that might be regarded as redundant or duplicate publication of the same or very similar work. The author must alert the editor if the manuscript includes subjects about which the authors have published a previous report or have submitted a related report to another publication. Any such report must be referred to and refer- 
enced in the new paper. Copies of such material should be included with the submitted paper to help the editor decide how to handle the matter.

If redundant or duplicate publication is attempted or occurs without such notification, authors should expect editorial action to be taken. At the least, prompt rejection of the submitted manuscript should be expected. If the editor was not aware of the violations and the article has already been published, then a notice of redundant or duplicate publication will probably be published with or without the author's explanation or approval.

Preliminary reporting to public media, governmental agencies, or manufacturers, of scientific information described in a paper or a letter to the editor that has been accepted but not yet published violates the policies of many journals. Such reporting may be warranted when the paper or letter describes major therapeutic advances or public health hazards such as serious adverse effects of drugs, vaccines, other biological products, or medicinal devices, or reportable diseases. This reporting should not jeopardize publication, but should be discussed with and agreed upon by the editor in advance.

\section{III.D.3. Acceptable Secondary Publication}

Certain types of articles, such as guidelines produced by governmental agencies and professional organizations, may need to reach the widest possible audience. In such instances, editors sometimes choose deliberately to publish material that is also being published in other journals, with the agreement of the authors and the editors of those other journals. Secondary publication for various other reasons, in the same or another language, especially in other countries, is justifiable, and can be beneficial, provided all of the following conditions are met.

1. The authors have received approval from the editors of both journals; the editor concerned with secondary publication must have a photocopy, reprint, or manuscript of the primary version.

2. The priority of the primary publication is respected by a publication interval of at least one week (unless specifically negotiated otherwise by both editors).

3. The paper for secondary publication is intended for a different group of readers; an abbreviated version could be sufficient.

4. The secondary version faithfully reflects the data and interpretations of the primary version.

5. The footnote on the title page of the secondary version informs readers, peers, and documenting agencies that the paper has been published in whole or in part and states the primary reference. A suitable footnote might read: "This article is based on a study first reported in the [title of journal, with full reference].”

Permission for such secondary publication should be free of charge.

6 . The title of the secondary publication should indi- cate that it is a secondary publication (complete republication, abridged republication, complete translation, or abridged translation) of a primary publication. Of note, the National Library of Medicine does not consider translations to be "republications," and does not cite or index translations when the original article was published in a journal that is indexed in MEDLINE.

\section{III.D.4. Competing Manuscripts Based on the Same Study}

Publication of manuscripts to air co-investigators disputes may waste journal space and confuse readers. On the other hand, if editors knowingly publish a manuscript written by only some of a collaborating team, they could be denying the rest of the team their legitimate co authorship rights; they could also be denying the journal's readers access to legitimate differences of opinion about the interpretation of a study.

Two kinds of competing submissions are considered: submissions by coworkers who disagree on the analysis and interpretation of their study, and submissions by coworkers who disagree on what the facts are and which data should be reported.

Setting aside the unresolved question of ownership of the data, the following general observations may help editors and others dealing with these problems.

\section{III.D.4.a. Differences in Analysis or Interpretation}

If the dispute centers on the analysis or interpretation of data, the authors should submit a manuscript that clearly presents both versions. The difference of opinion should be explained in a cover letter. The normal process of peer and editorial review of the manuscript may help the authors to resolve their disagreement regarding analysis or interpretation.

If the dispute cannot be resolved and the study merits publication, both versions should be published. Options include publishing two papers on the same study, or a single paper with two analyses or interpretations. In such cases it would be appropriate for the editor to publish a statement outlining the disagreement and the journal's involvement in attempts to resolve it.

\section{III.D.4.b. Differences in Reported Methods or Results}

If the dispute centers on differing opinions of what was actually done or observed during the study, the journal editor should refuse publication until the disagreement is resolved. Peer review cannot be expected to resolve such problems. If there are allegations of dishonesty or fraud, editors should inform the appropriate authorities; authors should be notified of an editor's intention to report a suspicion of research misconduct.

\section{III.D.5. Competing Manuscripts Based on the Same Database}

Editors sometimes receive manuscripts from separate research groups that have analyzed the same data set, e.g., 
ICMJE Uniform Requirements for Manuscripts Submitted to Biomedical Journals: Writing and Editing for Biomedical Publication

from a public database. The manuscripts may differ in their analytic methods, conclusions, or both. Each manuscript should be considered separately. Where interpretations of the same data are very similar, it is reasonable but not necessary for editors to give preference to the manuscript that was received earlier. However, editorial consideration of multiple submissions may be justified in this circumstance, and there may even be a good reason for publishing more than one manuscript because different analytical approaches may be complementary and equally valid.

\section{III.E. Correspondence}

Biomedical journals should provide its readership with a mechanism for submitting comments, questions, or criticisms about published articles, as well as brief reports and commentary unrelated to previously published articles. This will likely, but not necessarily, take the form of a correspondence section or column. The authors of articles discussed in correspondence should be given an opportunity to respond, preferably in the same issue in which the original correspondence appears. Authors of correspondence should be asked to declare any competing or conflicting interests.

Published correspondence may be edited for length, grammatical correctness, and journal style. Alternatively, editors may choose to publish correspondence unedited for length or style, as for example in rapid response sections on the Internet; the journal should declare its editorial practice in this regard. Authors should approve editorial changes that alter the substance or tone of a letter or response.

Although editors have the prerogative to sift out correspondence material that is irrelevant, uninteresting, or lacking in cogency, they have a responsibility to allow a range of opinion to be expressed. The correspondence column should not be used merely to promote the journal's, or the editors', point of view. In all instances, editors must make an effort to screen out discourteous, inaccurate, or libelous statements, and should not allow ad hominem arguments intended to discredit opinions or findings.

In the interests of fairness and to keep correspondence within manageable proportions, journals may want to set time limits for responding to articles and correspondence, and for debate on a given topic. Journals should also decide whether they would notify authors when correspondence bearing on their published work is going to appear in standard or rapid response sections. Journals should also set policy with regard to the archiving of unedited correspondence that appears on line. These policies should be published both in print and electronic versions of the journal.

\section{III.F. Supplements, Theme Issues, and Special Series}

Supplements are collections of papers that deal with related issues or topics, are published as a separate issue of the journal or as part of a regular issue, and are usually funded by sources other than the journal's publisher. Supplements can serve useful purposes: education, exchange of research information, ease of access to focused content, and improved cooperation between academic and corporate entities. Because funding sources can bias the content of supplements through the choice of topics and viewpoints, journals should consider adopting the following principles. These same principles apply to theme issues or special series that have external funding and/or guest editors.

1. The journal editor must take full responsibility for the policies, practices, and content of supplements, including complete control of the decision to publish all portions of the supplement. Editing by the funding organization should not be permitted.

2. The journal editor must retain the authority to send supplement manuscripts for external peer review and to reject manuscripts submitted for the supplement. These conditions should be made known to authors and external supplement editors before beginning editorial work on the supplement.

3. The journal editor must approve the appointment of any external editor of the supplement and take responsibility for the work of the external editor.

4. The sources of funding for the research, publication, and the products the funding source make that are considered in the supplement should be clearly stated and prominently located in the supplement, preferably on each page. Whenever possible, funding should come from more than one sponsor.

5. Advertising in supplements should follow the same policies as those of the rest of the journal.

6. Journal editors must enable readers to distinguish readily between ordinary editorial pages and supplement pages.

7. Journal editors and supplement editors must not accept personal favors or personal remuneration from sponsors of supplements.

8. Secondary publication in supplements (republication of papers previously published elsewhere) should be clearly identified by the citation of the original paper. Supplements should avoid redundant or duplicate publication. Supplements should not republish research results, but the republication of guidelines or other material in the public interest might be appropriate.

9. The principles of authorship and potential conflict of interest disclosure articulated elsewhere in this document should apply to supplements.

\section{III.G. Electronic Publishing}

Most biomedical journals are now published in electronic as well as print versions, and some are published in electronic form only. Electronic publishing (which includes the Internet) is publishing. In the interests of clarity and consistency, the medical and health information published on the Internet should follow the recommendations in this document whenever possible.

The nature of electronic publication requires some special considerations, both within and beyond this document. At a minimum, websites should indicate the fol- 
lowing: names, appropriate credentials, affiliations, and relevant conflicts of interest of editors, authors, and contributors; documentation and attribution of references and sources for all content; information about copyright; disclosure of site ownership; and disclosure of sponsorship, advertising, and commercial funding.

Linking from one health or medical Internet site to another may be perceived as an implicit recommendation of the quality of the second site. Journals thus should exercise caution in linking to other sites; when users are linking to another site, it may be helpful to provide an explicit message to that they are leaving the journal's site. If links to other sites are posted as a result of financial considerations, such should be clearly indicated. All dates of content posting and updating should be indicated. In electronic layout as in print, advertising and promotional messages should not be juxtaposed with editorial content, and commercial content should be clearly identifiable as such.

Electronic publication is an area that is in flux. Editors should develop, make available to authors, and implement policies on issues unique to electronic publishing. These issues include archiving, error correction, version control, and choice of the electronic or print version of the journal as the journal of record, publication of ancillary material, and electronic publication.

\section{III.H. Advertising}

Most medical journals carry advertising, which generates income for their publishers, but advertising must not be allowed to influence editorial decisions. Journals should have formal, explicit, written policies for advertising in both print and electronic versions; website advertising policy should parallel policy for the print version as much as possible. Editors must have full and final authority for approving advertisements and enforcing advertising policy. Where independent bodies for reviewing advertising exist editors should make use of their judgments.

Readers should be able to distinguish readily between advertising and editorial material. The juxtaposition of editorial and advertising material on the same products or subjects should be avoided. Interleafing advertising pages within articles discourages readers by interrupting the flow of editorial content, and should be discouraged. Advertising should not be sold on the condition that it will appear in the same issue as a particular article.

Journals should not be dominated by advertising, but editors should be careful about publishing advertisements from only one or two advertisers, as readers may perceive that these advertisers have influenced the editor.

Journals should not carry advertisements for products that have proved to be seriously harmful to health-for example, tobacco. Editors should ensure that existing regulatory or industry standards for advertisements specific to their country are enforced, or develop their own standards. The interests of organizations or agencies should not control classified and other non-display advertising, except where required by law. Finally, editors should consider all criticisms of advertisements for publication.

\section{III.I. Medical Journals and the General Media}

The public's interest in news of medical research has led the popular media to compete vigorously to get information about research as soon as possible. Researchers and institutions sometimes encourage the reporting of research in the non-medical media before full publication in a scientific journal by holding a press conference or giving interviews.

The public is entitled to important medical information without unreasonable delay, and editors have a responsibility to play their part in this process. Biomedical journals are published primarily for their readers, but the general public has a legitimate interest in their content; an appropriate balance should therefore guide journals' interaction with the media between these complementary interests. Doctors in practice need to have reports available in full detail before they can advise their patients about the reports' conclusions. Moreover, media reports of scientific research before the work has been peer reviewed and fully published may lead to the dissemination of inaccurate or premature conclusions.

An embargo system has been established in some countries to prevent publication of stories in the general media before the original paper on which they are based appears in the journal. The embargo creates a "level playing field," which most reporters appreciate since it minimizes the pressure on them to publish stories which they have not had time to prepare carefully. Consistency in the timing of public release of biomedical information is also important in minimizing economic chaos, since some articles contain information that has great potential to influence financial markets. On the other hand, the embargo system has been challenged as being self-serving of journals' interests, and impeding the rapid dissemination of scientific information.

Editors may find the following recommendations useful as they seek to establish policies on these issues.

- Editors can foster the orderly transmission of medical information from researchers, through peer-reviewed journals, to the public. This can be accomplished by an agreement with authors that they will not publicize their work while their manuscript is under consideration or awaiting publication and an agreement with the media that they will not release stories before publication in the journal, in return for which the journal will cooperate with them in preparing accurate stories.

- Editors need to keep in mind that an embargo system works on the honor system; no formal enforcement or policing mechanism exists. The decision of any significant number of media outlets, or of biomedical journals, not to respect the embargo system would therefore lead to its rapid dissolution. 
ICMJE Uniform Requirements for Manuscripts Submitted to Biomedical Journals: Writing and Editing for Biomedical Publication

- Very little medical research has such clear and urgently important clinical implications for the public's health that the news must be released before full publication in a journal. In such exceptional circumstances, however, appropriate authorities responsible for public health should make the decision and should be responsible for the advance dissemination of information to physicians and the media. If the author and the appropriate authorities wish to have a manuscript considered by a particular journal, the editor should be consulted before any public release. If editors accept the need for immediate release, they should waive their policies limiting prepublication publicity.

- Policies designed to limit prepublication publicity should not apply to accounts in the media of presentations at scientific meetings or to the abstracts from these meetings (see Redundant Publication). Researchers who present their work at a scientific meeting should feel free to discuss their presentations with reporters, but they should be discouraged from offering more detail about their study than was presented in their talk.

- When an article is soon to be published, editors should help the media prepare accurate reports by providing news releases, answering questions, supplying advance copies of the journal, or referring reporters to the appropriate experts. Most responsible reporters find this assistance should be contingent on the media's cooperation in timing their release of stories to coincide with the publication of the article.

- Editors, authors, and the media should apply the above stated principles to material released early in electronic versions of journals.

\section{III.J. Obligation to Register Clinical Trials}

The ICMJE member journals will require, as a condition of consideration for publication, registration in a public trials registry. Trials must register at or before the onset of patient enrollment. This policy applies to any clinical trial starting enrollment after July 1, 2005. For trials that began enrollment prior to this date, the ICMJE member journals will require registration by September 13, 2005 before considering the trial for publication. We speak only for ourselves, but we encourage editors of other biomedical journals to adopt similar policies. For this purpose, the ICMJE defines a clinical trial as any research project that prospectively assigns human subjects to intervention or comparison groups to study the cause-and-effect relationship between a medical intervention and a health outcome. Studies designed for other purposes, such as to study pharmacokinetics or major toxicity (e.g., phase I trials), would be exempt.

The ICMJE does not advocate one particular registry, but its member journals will require authors to register their trial in a registry that meets several criteria. The reg- istry must be accessible to the public at no charge. It must be open to all prospective registrants and managed by a not-for-profit organization. There must be a mechanism to ensure the validity of the registration data, and the registry should be electronically searchable. An acceptable registry must include at minimum the following information: a unique identifying number, a statement of the intervention (or interventions) and comparison (or comparisons) studied, a statement of the study hypothesis, definitions of the primary and secondary outcome measures, eligibility criteria, key trial dates (registration date, anticipated or actual start date, anticipated or actual date of last follow-up, planned or actual date of closure to data entry, and date trial data considered complete), target number of subjects, funding source, and contact information for the principal investigator.

\section{Manuscript Preparation and Submission IV.A. Preparing a Manuscript for Submission to a Biomedical Journal}

Editors and reviewers spend many hours reading manuscripts, and therefore appreciate receiving with manuscripts that are easy to read and edit. Much of the information in journals' instructions to authors is designed to accomplish that goal in ways that meet each journal's particular editorial needs. The guidance that follows provides a general background and rationale for preparing manuscripts for any journal.

\section{IV.A.1. General Principles and Reporting Guidelines}

\section{IV.A.1.a. General Principles for Manuscript Preparation}

The text of observational and experimental articles is usually (but not necessarily) divided into sections with the headings Introduction, Methods, Results, and Discussion. This so-called "IMRAD" structure is not simply an arbitrary publication format, but rather a direct reflection of the process of scientific discovery. Long articles may need subheadings within some sections (especially the Results and Discussion sections) to clarify their content. Other types of articles, such as case reports, reviews, and editorials, are likely to need other formats.

Publication in electronic formats has created opportunities for adding details or whole sections in the electronic version only, layering information, cross-linking or extracting portions of articles, and the like. Authors need to work closely with editors in developing or using such new publication formats and should submit material for potential supplementary electronic formats for peer review.

Double spacing of all portions of the manuscriptincluding the title page, abstract, text, acknowledgments, references, individual tables, and legends-and generous margins make it possible for editors and reviewers to edit the text line by line, and add comments and queries, directly on the paper copy. If manuscripts are submitted electronically, the files should be double spaced, because 
the manuscript may need to be printed out for reviewing and editing.

During the editorial process reviewers and editors frequently need to refer to specific portions of the manuscript, which is difficult unless the pages are numbered. Authors should therefore number all of the pages of the manuscript consecutively, beginning with the title page.

\section{V.A.1.b. Reporting Guidelines for Specific Study Designs}

Research reports frequently omit important information. The general requirements listed in the next section relate to reporting essential elements for all study designs. Authors are encouraged in addition to consult reporting guidelines relevant to their specific research design. For reports of randomized controlled trials authors should refer to the CONSORT statement (www.consort-statement .org). This guideline provides a set of recommendations comprising a list of items to report and a patient flow diagram. Reporting guidelines have also been developed for a number of other study designs that some journals may ask authors to follow. Some of these reporting guidelines can also be found at www.consort-statement.org. Authors should consult the information for authors of the journal they have chosen.

\section{IV.A.2. Title Page}

The title page should carry the following information:

1. The title of the article. Concise titles are easier to read than long, convoluted ones. Titles that are too short may, however, lack important information, such as study design (which is particularly important in identifying randomized controlled trials). Authors should include all information in the title that will make electronic retrieval of the article both sensitive and specific.

2. Authors' names and institutional affiliations. Some journals publish each author's highest academic degree(s), while others do not.

3. The name of the department(s) and institution(s) to which the work should be attributed.

4. Disclaimers, if any.

5. Corresponding authors. The name, mailing address, telephone and fax numbers, and e-mail address of the author responsible for correspondence about the manuscript (the "corresponding author;" this author may or may not be the "guarantor" for the integrity of the study as a whole, if someone is identified in that role. The corresponding author should indicate clearly whether his or her e-mail address is to be published.

6 . The name and address of the author to whom requests for reprints should be addressed or a statement that reprints will not be available from the authors.

7. Source(s) of support in the form of grants, equipment, drugs, or all of these.

8. A running head. Some journals request a short running head or foot line, usually of no more than 40 characters (count letters and spaces) at the foot of the title page. Running heads are published in most journals, but are also sometimes used within the editorial office for filing and locating manuscripts.

9. Word counts. A word count for the text only (excluding abstract, acknowledgments, figure legends, and references) allows editors and reviewers to assess whether the information contained in the paper warrants the amount of space devoted to it, and whether the submitted manuscript fits within the journal's word limits. A separate word count for the Abstract is also useful for the same reason.

10. The number of figures and tables. It is difficult for editorial staff and reviewers to tell if the figures and tables that should have accompanied a manuscript were actually included unless the numbers of figures and tables that belong to the manuscript are noted on the title page.

\section{IV.A.3. Conflict of Interest Notification Page}

To prevent the information on potential conflict of interest for authors from being overlooked or misplaced, it is necessary for that information to be part of the manuscript. It should therefore also be included on a separate page or pages immediately following the title page. However, individual journals may differ in where they ask authors to provide this information and some journals do not send information on conflicts of interest to reviewers. (See Section II.D. Conflicts of Interest)

\section{IV.A.4. Abstract and Key Words}

An abstract (requirements for length and structured format vary by journal) should follow the title page. The abstract should provide the context or background for the study and should state the study's purposes, basic procedures (selection of study subjects or laboratory animals, observational and analytical methods), main findings (giving specific effect sizes and their statistical significance, if possible), and principal conclusions. It should emphasize new and important aspects of the study or observations.

Because abstracts are the only substantive portion of the article indexed in many electronic databases, and the only portion many readers read, authors need to be careful that abstracts reflect the content of the article accurately. Unfortunately, many abstracts disagree with the text of the article (6). The format required for structured abstracts differs from journal to journal, and some journals use more than one structure; authors should make it a point prepare their abstracts in the format specified by the journal they have chosen.

Some journals request that, following the abstract, authors provide, and identify as such, 3 to 10 key words or short phrases that capture the main topics of the article. These will assist indexers in cross-indexing the article and may be published with the abstract. Terms from the Medical Subject Headings (MeSH) list of Index Medicus should be used; if suitable MeSH terms are not yet available for recently introduced terms, present terms may be used. 


\section{IV.A.5. Introduction}

Provide a context or background for the study (i.e., the nature of the problem and its significance). State the specific purpose or research objective of, or hypothesis tested by, the study or observation; the research objective is often more sharply focused when stated as a question. Both the main and secondary objectives should be made clear, and any pre-specified subgroup analyses should be described. Give only strictly pertinent references and do not include data or conclusions from the work being reported.

\section{IV.A.6. Methods}

The Methods section should include only information that was available at the time the plan or protocol for the study was written; all information obtained during the conduct of the study belongs in the Results section.

\section{IV.A.6.a. Selection and Description of Participants}

Describe your selection of the observational or experimental participants (patients or laboratory animals, including controls) clearly, including eligibility and exclusion criteria and a description of the source population. Because the relevance of such variables as age and sex to the object of research is not always clear, authors should explain their use when they are included in a study report; for example, authors should explain why only subjects of certain ages were included or why women were excluded. The guiding principle should be clarity about how and why a study was done in a particular way. When authors use variables such as race or ethnicity, they should define how they measured the variables and justify their relevance.

\section{IV.A.6.b. Technical information}

Identify the methods, apparatus (give the manufacturer's name and address in parentheses), and procedures in sufficient detail to allow other workers to reproduce the results. Give references to established methods, including statistical methods (see below); provide references and brief descriptions for methods that have been published but are not well known; describe new or substantially modified methods, give reasons for using them, and evaluate their limitations. Identify precisely all drugs and chemicals used, including generic name(s), dose(s), and route(s) of administration.

Authors submitting review manuscripts should include a section describing the methods used for locating, selecting, extracting, and synthesizing data. These methods should also be summarized in the abstract.

\section{IV.A.6.c. Statistics}

Describe statistical methods with enough detail to enable a knowledgeable reader with access to the original data to verify the reported results. When possible, quantify findings and present them with appropriate indicators of measurement error or uncertainty (such as confidence intervals). Avoid relying solely on statistical hypothesis testing, such as the use of $\mathrm{P}$ values, which fails to convey important information about effect size. References for the design of the study and statistical methods should be to standard works when possible (with pages stated). Define statistical terms, abbreviations, and most symbols. Specify the computer software used.

\section{IV.A.7. Results}

Present your results in logical sequence in the text, tables, and illustrations, giving the main or most important findings first. Do not repeat in the text all the data in the tables or illustrations; emphasize or summarize only important observations. Extra or supplementary materials and technical detail can be placed in an appendix where it will be accessible but will not interrupt the flow of the text; alternatively, it can be published only in the electronic version of the journal.

When data are summarized in the Results section, give numeric results not only as derivatives (for example, percentages) but also as the absolute numbers from which the derivatives were calculated, and specify the statistical methods used to analyze them. Restrict tables and figures to those needed to explain the argument of the paper and to assess its support. Use graphs as an alternative to tables with many entries; do not duplicate data in graphs and tables. Avoid non-technical uses of technical terms in statistics, such as "random" (which implies a randomizing device), "normal," "significant," "correlations," and "sample."

Where scientifically appropriate, analyses of the data by variables such as age and sex should be included.

\section{IV.A.8. Discussion}

Emphasize the new and important aspects of the study and the conclusions that follow from them. Do not repeat in detail data or other material given in the Introduction or the Results section. For experimental studies it is useful to begin the discussion by summarizing briefly the main findings, then explore possible mechanisms or explanations for these findings, compare and contrast the results with other relevant studies, state the limitations of the study, and explore the implications of the findings for future research and for clinical practice.

Link the conclusions with the goals of the study but avoid unqualified statements and conclusions not adequately supported by the data. In particular, authors should avoid making statements on economic benefits and costs unless their manuscript includes the appropriate economic data and analyses. Avoid claiming priority and alluding to work that has not been completed. State new hypotheses when warranted, but clearly label them as such.

\section{IV.A.9. References}

\section{IV.A.9.a. General Considerations Related to References}

Although references to review articles can be an efficient way of guiding readers to a body of literature, review articles do not always reflect original work accurately. 
Readers should therefore be provided with direct references to original research sources whenever possible. On the other hand, extensive lists of references to original work on a topic can use excessive space on the printed page. Small numbers of references to key original papers will often serve as well as more exhaustive lists, particularly since references can now be added to the electronic version of published papers, and since electronic literature searching allows readers to retrieve published literature efficiently.

Avoid using abstracts as references. References to papers accepted but not yet published should be designated as "in press" or "forthcoming"; authors should obtain written permission to cite such papers as well as verification that they have been accepted for publication. Information from manuscripts submitted but not accepted should be cited in the text as "unpublished observations" with written permission from the source.

Avoid citing a "personal communication" unless it provides essential information not available from a public source, in which case the name of the person and date of communication should be cited in parentheses in the text. For scientific articles, authors should obtain written permission and confirmation of accuracy from the source of a personal communication.

Some journals check the accuracy of all reference citations, but not all journals do so, and citation errors sometimes appear in the published version of articles. To minimize such errors, authors should therefore verify references against the original documents.

\section{IV.A.9.b. Reference Style and Format}

The Uniform Requirements style is based largely on an ANSI standard style adapted by the National Library of Medicine (NLM) for its databases. (7) For samples of reference citation formats, authors should consult http://www .nlm.nih.gov/bsd/uniform_requirements.html.

References should be numbered consecutively in the order in which they are first mentioned in the text. Identify references in text, tables, and legends by Arabic numerals in parentheses. References cited only in tables or figure legends should be numbered in accordance with the sequence established by the first identification in the text of the particular table or figure. The titles of journals should be abbreviated according to the style used in Index Medicus. Consult the List of Journals Indexed for MEDLINE, published annually as a separate publication by the National Library of Medicine. The list can also be obtained through the Library's web site (http://www.nlm.nih.gov/tsd/serials/lji.html).

Journals vary on whether they ask authors to cite electronic references within parentheses in the text or in numbered references following the text. Authors should consult with the journal that they plan to submit their work to.

\section{IV.A.10. Tables}

Tables capture information concisely, and display it efficiently; they also provide information at any desired level of detail and precision. Including data in tables rather than text frequently makes it possible to reduce the length of the text.

Type or print each table with double spacing on a separate sheet of paper. Number tables consecutively in the order of their first citation in the text and supply a brief title for each. Do not use internal horizontal or vertical lines. Give each column a short or abbreviated heading. Authors should place explanatory matter in footnotes, not in the heading. Explain in footnotes all nonstandard abbreviations. For footnotes use the following symbols, in sequence:

$$
{ }^{*}, \dagger, \ddagger, \S, \|,{ }^{*} \text {,十†,キキ }
$$

Identify statistical measures of variations, such as standard deviation and standard error of the mean.

Be sure that each table is cited in the text.

If you use data from another published or unpublished source, obtain permission and acknowledge them fully.

Additional tables containing backup data too extensive to publish in print may be appropriate for publication in the electronic version of the journal, deposited with an archival service, or made available to readers directly by the authors. In that event an appropriate statement will be added to the text. Submit such tables for consideration with the paper so that they will be available to the peer reviewers.

\section{IV.A.11. Illustrations (Figures)}

Figures should be either professionally drawn and photographed, or submitted as photographic quality digital prints. In addition to requiring a version of the figures suitable for printing, some journals now ask authors for electronic files of figures in a format (e.g., JPEG or GIF) that will produce high quality images in the web version of the journal; authors should review the images of such files on a computer screen before submitting them, to be sure they meet their own quality standard.

For x-ray films, scans, and other diagnostic images, as well as pictures of pathology specimens or photomicrographs, send sharp, glossy, black-and-white or color photographic prints, usually $127 \times 173 \mathrm{~mm}(5 \times 7$ inches $)$. Although some journals redraw figures, many do not. Letters, numbers, and symbols on Figures should therefore be clear and even throughout, and of sufficient size that when reduced for publication each item will still be legible. Figures should be made as self-explanatory as possible, since many will be used directly in slide presentations. Titles and detailed explanations belong in the legends, however, not on the illustrations themselves.

Photomicrographs should have internal scale markers. Symbols, arrows, or letters used in photomicrographs should contrast with the background.

If photographs of people are used, either the subjects must not be identifiable or their pictures must be accompanied by written permission to use the photograph (see 
Section III.D.4.a). Whenever possible permission for publication should be obtained.

Figures should be numbered consecutively according to the order in which they have been first cited in the text. If a figure has been published, acknowledge the original source and submit written permission from the copyright holder to reproduce the material. Permission is required irrespective of authorship or publisher except for documents in the public domain.

For illustrations in color, ascertain whether the journal requires color negatives, positive transparencies, or color prints. Accompanying drawings marked to indicate the region to be reproduced might be useful to the editor. Some journals publish illustrations in color only if the author pays for the extra cost.

Authors should consult the journal about requirements for figures submitted in electronic formats.

\section{IV.A.12. Legends for Illustrations (Figures)}

Type or print out legends for illustrations using double spacing, starting on a separate page, with Arabic numerals corresponding to the illustrations. When symbols, arrows, numbers, or letters are used to identify parts of the illustrations, identify and explain each one clearly in the legend. Explain the internal scale and identify the method of staining in photomicrographs.

\section{IV.A.13. Units of Measurement}

Measurements of length, height, weight, and volume should be reported in metric units (meter, kilogram, or liter) or their decimal multiples.

Temperatures should be in degrees Celsius. Blood pressures should be in millimeters of mercury, unless other units are specifically required by the journal.

Journals vary in the units they use for reporting hematological, clinical chemistry, and other measurements. Authors must consult the information for authors for the particular journal and should report laboratory information in both the local and International System of Units (SI). Editors may request that the authors before publication add alternative or non-SI units, since SI units are not universally used. Drug concentrations may be reported in either SI or mass units, but the alternative should be provided in parentheses where appropriate.

\section{IV.A.14. Abbreviations and Symbols}

Use only standard abbreviations; the use of non-standard abbreviations can be extremely confusing to readers. Avoid abbreviations in the title. The full term for which an abbreviation stands should precede its first use in the text unless it is a standard unit of measurement.

\section{IV.B Sending the Manuscript to the Journal}

An increasing number of journals now accept electronic submission of manuscripts, whether on disk, as attachments to electronic mail, or by downloading directly onto the journal website. Electronic submission saves time as well as postage costs, and allows the manuscript to be handled in electronic form throughout the editorial process (for example, when it is sent out for review). When submitting a manuscript electronically, authors should consult with the instructions for authors of the journal they have chosen for their manuscript.

If a paper version of the manuscript is submitted, send the required number of copies of the manuscript and figures; they are all needed for peer review and editing, and editorial office staff cannot be expected to make the required copies.

Manuscripts must be accompanied by a cover letter, which should include the following information.

- A full statement to the editor about all submissions and previous reports that might be regarded as redundant publication of the same or very similar work. Any such work should be referred to specifically, and referenced in the new paper. Copies of such material should be included with the submitted paper, to help the editor decide how to handle the matter.

- A statement of financial or other relationships that might lead to a conflict of interest, if that information is not included in the manuscript itself or in an authors' form

- A statement that the manuscript has been read and approved by all the authors, that the requirements for authorship as stated earlier in this document have been met, and that each author believes that the manuscript represents honest work, if that information is not provided in another form (see below); and

- The name, address, and telephone number of the corresponding author, who is responsible for communicating with the other authors about revisions and final approval of the proofs, if that information is not included on the manuscript itself.

The letter should give any additional information that may be helpful to the editor, such as the type or format of article in the particular journal that the manuscript represents. If the manuscript has been submitted previously to another journal, it is helpful to include the previous editor's and reviewers' comments with the submitted manuscript, along with the authors' responses to those comments. Editors encourage authors to submit these previous communications and doing so may expedite the review process.

Many journals now provide a pre-submission checklist that assures that all the components of the submission have been included. Some journals now also require that authors complete checklists for reports of certain study types (e.g., the CONSORT checklist for reports of randomized controlled trials). Authors should look to see if the journal uses 
such checklists, and send them with the manuscript if they are requested.

Copies of any permission to reproduce published material, to use illustrations or report information about identifiable people, or to name people for their contributions must accompany the manuscript.

\section{References}

\section{A. References Cited in this Document}

1. Davidoff $\mathrm{F}$ for the CSE Task Force on Authorship. Who's the Author? Problems with Biomedical Authorship, and Some Possible Solutions. Science Editor. July-August 2000: Volume 23 - Number 4: 111-119.

2. Yank V, Rennie D. Disclosure of researcher contributions: a study of original research articles in The Lancet. Ann Intern Med. 1999 Apr 20;130(8):661-70.

3. Flanagin A, Fontanarosa PB, DeAngelis CD. Authorship for research groups. JAMA. 2002;288:3166-68.

4. Peer Review in Health Sciences. F Godlee, T Jefferson. London: BMJ Books, 1999.

5. World Medical Association Declaration of Helsinki: ethical principles for medical research involving human subjects. JAMA. 2000 Dec 20;284(23):3043-5.

6. Pitkin RM, Branagan MA, Burmeister LF. Accuracy of data in abstracts of published research articles. JAMA. 1999 Mar 24-31;281(12):1110-1.

7. Patrias K. National Library of Medicine recommended formats for bibliographic citation. Bethesda (MD): The Library; 1991.

\section{B. Other Sources of Information Related to Biomedical Journals}

World Association of Medical Editors (WAME) www .WAME.org

Council of Science Editors (CSE) www.councilscience editors.org

European Association of Science Editors (EASE) www.ease .org.uk

Cochrane Collaboration www.cochrane.org

The Mulford Library, Medical College of Ohio www.mco .edu/lib/instr/libinsta.html

\section{Aвout The International Committee of MEDICAL JOURNAL EDITORS}

The International Committee of Medical Journal Editors (ICMJE) is a group of general medical journal editors whose participants meet annually and fund their work on the Uniform Requirements for Manuscripts. The ICMJE invites comments on this document and suggestions for agenda items.

\section{Authors of The Uniform ReQUiRements for ManusCRIPTS SUbMitTed to BIOMEdical Journals}

The ICMJE participating journals and organizations and their representatives who approved the revised Uniform Requirements for Manuscripts in October 2004 include Annals of Internal Medicine, Canadian Medical Association Journal, Croatian Medical Journal, Journal of the American Medical Association, Nederlands Tijdschrift voor Geneeskunde, New England Journal of Medicine, New Zealand Medical Journal, The Lancet, The Medical Journal of Australia,Tidsskrift for Den Norske Llegeforening, Ugeskrift for Laeger, and the U.S. National Library of Medicine.

\section{Vill. Use, Distribution, and Translation of the UNIFORM REQUIREMENTS}

Users may print, copy, and distribute this document without charge for not-for-profit, educational purpose. The ICMJE does not stock paper copies (reprints) of this document.

The ICMJE policy is for interested organizations to link to the official English language document at www .ICMJE.org. The ICMJE does not endorse posting of the document on web sites other than www.ICMJE.org.

The ICMJE welcomes organizations to reprint or translate this document into languages other than English for non-profit purposes. However, the ICMJE does not have the resources to translate, to back translate, or to approve reprinted or translated versions of the document. Thus, any translations should prominently include the following statement: "This is a reprint/ (insert language name) language translation of the ICMJE Uniform Requirements for Manuscripts Submitted to Biomedical Journals. (insert name of organization) prepared this reprint/translation with support from (insert name of funding source, if any). The ICMJE has neither endorsed nor approved the contents of this reprint/ translation. The ICMJE periodically updates the Uniform Requirements, so this reprint/translation prepared on (insert date) may not accurately represent the current official version at www.ICMJE.org. The official version of the Uniform Requirements for Manuscripts Submitted to Biomedical Journals is located at www.ICMJE.org."

\section{INQUIRIES}

Inquiries about the Uniform Requirements should be sent to Christine Laine, MD, MPH at the ICMJE Secretariat office, American College of Physicians, 190 N. Independence Mall West, Philadelphia, PA 19106-1572, USA. phone, 215-351-2660; fax 215-351-2644; e-mail claine $@$ acponline.org. Please do not direct inquiries about individual journal styles or policies to the ICMJE secretariat office. 